\title{
A Medical Student's Elective Experience in Pediatric Rheumatology through the Canadian Rheumatology Association
}

\author{
Laura Sheriff \\ Faculty of Medicine, University of Ottawa, Ontario, Canada
}

\section{ABSTRACT}

This elective report provides an overview of the experience of a first-year medical student completing a pediatric rheumatology elective through the Canadian Rheumatology Association (CRA). Students apply to work with a rheumatologist and experience alternating schedules between inpatient and outpatient clinical medicine over the course of the summer. This elective is unique, as it exposes pre-clerkship medical students to learning experiences that will prepare them for clerkship and beyond. It provides practical experience as well as insight into research within the specialty at a world-renowned Canadian academic institution.

RÉSUMÉ

Ce rapport de stage donne un survol sur l'expérience d'un étudiant en médecine de première année complétant un stage en rhumatologie pédiatrique par l'entremise de la Société canadienne de rhumatologie (SCR). Les étudiants peuvent faire demande pour travailler avec un rhumatologiste afin d'avoir une opportunité de vivre un horaire alternant entre des soins externes et des soins hospitaliers, au cours de l'été. Ce stage est unique : il expose aux étudiants de médecine au préexternat des expériences d'apprentissage qui leur préparent pour l'externat et l'avenir. Il offre des opportunités pratiques ainsi qu'un aperçu de la recherche dans cette spécialité ; tout dans un établissement scolaire canadien mondialement connut.

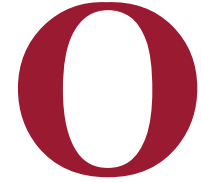

n my first day of work, I set my alarm early to account for any Toronto subway delays, and inevitably arrived to work with ample time to spare. I would be spending the next six weeks working in the Rheumatology Division of the Hospital for Sick Children (SickKids), as part of a clinical studentship through the Canadian Rheumatology Association (CRA). Upon entering the doors of SickKids on my first day, I felt both out of place and in awe, but excited to learn in this new and foreign environment.

Every summer across Canada, the CRA offers pre-clerkship medical students the opportunity to work with an adult or pediatric rheumatologist in order to observe and practice their clinical skills. I was interested in this program because I enjoyed the rheumatology lectures given in my first semester of medical school, and knew that if I did not seize this opportunity I would not encounter this content again until clerkship. I specifically chose to apply to work with a pediatric rheumatologist for the opportunity to explore my interest in pediatrics, and meet and work alongside the physicians at SickKids. Therefore, this program is a useful opportunity to learn more about the subspecialty of rheumatology for students who are considering applying to Internal Medicine or Pediatrics residency programs due to the availability of both adult and pediatric rheumatologists. My learning objectives for the program were to explore the field of pediatric rheumatology, gain experience observing and performing histories, physical exams, and procedures such as joint injections on pediatric patients, as well as learn about the lifestyle of this subspecialty in pediatrics.

\section{DISCUSSION}

Over the course of six weeks I was made to feel like part of the team and truly experienced the day-to-day life of a pediatric rheumatology fellow by participating in journal clubs, teaching sessions, academic half-days, and grand rounds. The program consists of working alongside staff physicians, clinical fellows, pediatric residents, physical therapists, and nurses. I had the opportunity to alternate between spending weeks in outpatient clinics and working with the inpatient care team. There are various clinics scheduled throughout the week, including the General Rheumatology, Lupus, Juvenile Dermatomyositis, and Vasculitis clinics. When treating inpatients, I had many opportunities to work closely with other care teams and learn about other specialties as well, such as general pediatrics, nephrology, dermatology, neonatology, radiology, and pathology and gained an appreciation for the multi-systemic

Keywords: Pediatrics; Rheumatology; The Hospital of Sick Children; Canada 
and interdisciplinary nature of this specialty. Additionally, I observed how rheumatologists and pediatric anesthesiologists collaborate, when every Friday, the week culminated in a fellow performing sedated joint injections on patients with joint effusions. I really enjoyed the collaborative atmosphere and am grateful to my seniors for welcoming me into the world of clinical medicine early on in my medical career. I appreciate their teaching and mentorship and had many opportunities to practice taking histories on patients, physical exams, and putting in notes after patient encounters. My gratitude also extends to all of the fellows who took time out of their busy schedules to work with me and provide informal teaching sessions and advice.

During this elective, I increased my knowledge and skills and grew as both a clinician and a person. For example, I am much more equipped with the knowledge necessary to approach the differential diagnosis of a monoarthritis, apply the classification criteria for Juvenile Idiopathic Arthritis (JIA) and Systemic Lupus Erythematous (SLE), and examine a child using the Pediatric Gait Arms Legs and Spine (pGALS) screening approach. I was also able to practice clinical exam skills such as performing a joint exam through inspection, palpation, range of motion, and special tests for fluid to correctly identify a joint effusion. I became more comfortable with my cardiorespiratory, abdominal, and skin examinations. At first it was difficult for me to examine a patient and competently assess and form an impression about all of these findings, however I am beginning to feel more confident with these skills. With increased patient exposure and continued practice of my history taking and physical exam skills I foresee myself becoming much more capable by the time I begin my clerkship. One highlight of this experience was following my own inpatient for the first time, presenting his case, building a relationship with the patient and his family, checking his chart every morning for new results, and updating the team about his status. I learned how important it is to know your patient and communicate well so that the care team can succeed.

One aspect of the subspecialty of rheumatology that I discovered I really enjoy is the longstanding impact we can make on the lives of patients living with a chronic disease. For example, many of the patients I saw in the clinic had been diagnosed JIA when they were young children. Seeing them now as fully functioning adolescents, with active lives and minimal functional impairments due to the great care they have received, was really motivating for me. I learned that I would be very satisfied treating patients with chronic diseases so that I can follow them throughout their lives and provide the best possible care to minimize the impacts of their disease. One particular patient interaction that stands out was a teenaged female who had been diagnosed with JIA at the age of two and was encouraged by her physician to become active at the time. Because her disease is currently so well controlled, she is able to actively participate in competitive dance, and was invited to perform at a parade at a popular amusement park. This would not be possible without her resilience as well as the hard work and efforts of her care team. I also enjoyed interacting with the SLE patient population, which mainly consisted of adolescent females. Many had minimal clinical findings or disease impairments and were able to fully participate in school and activities. Many were nearing the end of high school and making decisions regarding future education and career plans. I find these interactions to be the most meaningful and appreciate the continuity of care we are able to provide as patients transition through different stages of life. Additionally, I learned that even though we see patients from a rheumatologic perspective, it is also essential to approach the patient from a broad perspective and consider other causes of their disease, such as infection, malignancy, or other systems. These lessons are essential throughout the training of both internists and pediatricians, and this program therefore benefits students interested in both of these fields.

\section{FINAL REFLECTIONS}

Spending six weeks at one of the best academic centres in the world, I was also able to learn about myself and identify areas where I can improve in the future. For example, although I gained more confidence in clinical encounters, I think I could have been more assertive and taken more initiative by requesting more responsibility. I learned that even though it may seem difficult or daunting, the best way to make the most of my medical education is by being an active, motivated team member that comes ready to learn each and every day. I realized that if you do not take risks, you will not learn. I recommend this elective to any pre-clerkship student who wishes to gain experience and confidence prior to beginning clerkship. This is a unique opportunity that places the expectations of upper year medical students on pre-clerkship medical students. Additionally, this elective is located very conveniently because students can apply to rheumatologists from all across Canada, providing the chance to spend their summer at home or explore a new city. As the summer progressed I noticed myself becoming more confident charting notes and seeing patients on my own, and 
this is a skill I will have to continue to build upon. This experience will help prepare me for my future medical career by instilling in me knowledge, skills, and a more positive attitude to facing challenges. These new insights will help me succeed in any specialty of medicine I decide to pursue in the future. I encourage everyone to seek out unfamiliar and exciting learning opportunities, internationally or locally, and step outside of their comfort zones in an effort to accomplish something new.

\section{ACKNOWLEDGEMENTS}

Thank you to all of the staff members, fellows, residents, and the entire team at SickKids for the warm welcome to the specialty of Pediatric Rheumatology, and to the CRA for organizing this unique elective opportunity. 